\title{
A CONTROVÉRSIA DE HEGEL E SCHOPENHAUER EM TORNO DAS RELAÇÕES ENTRE A VIDA E A VERDADE
}

Julio Cabrera*

SÍNTESE - Como um fato histórico, Hegel e Schopenhauer defenderam um conjunto de idéias que, em geral, são consideradas como irremissivelmente antagônicas e claramente irreconciliáveis. Este artigo visa a mostrar que a controvérsia real (não meramente histórica) entre Hegel e Schopenhauer assenta, paradoxalmente, num certo fundamento comum de intuições básicas atinentes às relações entre Vida e Conceito, apesar de discordarem em aspectos mais especificos do problema. Os conceitos serão considerados por ambos os filósofos, não como estruturas plenamente objetivas, mas como entidades animadas, interna e formalmente, por uma certa espécie de "vitalidade". A discordância real e profunda no pensamento filosófico de Hegel e Schopenhauer repousa, em última análise - tal é minha posição - nas diferenças do modo peculiar de compreender e desenvolver essa "vitalidade de conceitos", formal e interna, concebida como negatividade (Hegel) ou como uma espécie de configuração de vontade (Schopenhauer).
ABSTRACT - As a historical fact, Hegel and Schopenhauer held a set of ideas usually considered as irremisibly antagonistic and obviously irreconcilable. This paper attempts to show that the real (not merely historical) controversy between Hegel and Schopenhauer rests paradoxically on a certain common ground of basical intuitions concerning relationships between Life and Concept, despite disagreements on more specific aspects of the question. Concepts will be considered by both philosophers not as fully objective structures, but as entities internally and formally animated by a certain kind of "vitality". The real and deep disagreement between Hegel's and Schopenhauer's philosophical thought rests ultimately - I argue - on the differences in the peculiar way of understanding and developing this formal and internal "vitality of concepts", conceived as negativity (Hegel) or as a kind of volitional configuration (Schopenhauer).

\section{INTRODUÇÃO. Reflexões acerca de uma lacuna histórica}

Sabe-se que, historicamente, não existe nada que possa chamar-se uma controvérsia real entre Hegel e Schopenhauer sobre qualquer questão. Ao longo da obra de Hegel, não encontraremos nenhuma alusão à mera existência da obra ou da pessoa de Schopenhauer, nem mesmo naqueles assuntos nos quais pareceria

Departamento de Filosofia, Universidade de Brasilia, UnB.

\begin{tabular}{|l|l|l|l|l} 
VERITAS & Porto Alegre & v. 42 & $n^{2} 1$ & Março 1997 \\
\hline
\end{tabular}


inevitável mencioná-lo (por exemplo, na discussão hegeliana do princípio de razão suficiente ou na discussão em torno do Argumento Ontológico). Os motivos desta omissão total são extremamente complexos, além das explicações simplórias que 0 próprio Schopenhauer gostava de oferecer da mesma, justamente indignado pela indiferença de seus contemporâneos diante do valor de sua obra. Os motivos mais profundos deveriam ser detectados no próprio tecido dos pensamentos de Hegel e Schopenhauer. Havia obstáculos objetivos para que cada um deles não pudesse compreender o caráter revolucionário da proposta filosófica do outro.

Embora a omissão hegeliana de Schopenhauer seja um dado histórico, sustentarei que existe, igualmente, uma omissão schopenhauereana de Hegel. Não histórica, evidentemente, pois Hegel foi, como se sabe, um dos assuntos favoritos de Schopenhauer. Mas a ocorrência da palavra Hegel nos textos schopenhauereanos apenas parece um signo que funciona como estímulo - às vezes selvagem - para o desenvolvimento do próprio pensamento de Schopenhauer: o leitor atento poderá aproveitar, após o insulto, alguma idéia importante ou alguma intuição engenhosa. Visto do ponto de vista estritamente argumentativo, Hegel é omitido por Schopenhauer mediante uma omissão sutil: a omissão de um pensamento através da sua constante citação, através da permanente evocação nominal do omitido. Estamos, pois, na presença de uma mútua omissão filosófica, metade histórica, metade discursiva.

Esta mútua omissão é aqui simplesmente constatada. Poderíamos imaginar um Hegel e um Schopenhauer tolerantes e de boa vontade, lendo intensamente um a obra do outro, tentando honestamente entender-se e, não obstante, enfrentando inconvenientes estruturais de compreensão que não passariam apenas por uma pretensa "obscuridade" de Hegel ou por uma "superficialidade" do pensamento de Schopenhauer, mas por linhas mais profundas, por impossibilidades que ultrapassariam as individualidades desses dois filósofos. Proponho-me estudar aqui essa mútua impossibilidade, ou seja, como Schopenhauer e Hegel foram impossíveis um para o outro, mas tudo isso enquadrado dentro de uma problemática específica, as relações entre verdade e vida, ou entre as idéias filosóficas que são sustentadas e seus sustentadores humanos finitos. Hegel e Schopenhauer servirão aqui para refletir acerca desta problemática, não apenas porque a questão está, como pretendo mostrar, tematizada no próprio corpo das suas filosofias, mas porque a mesma está já refletida na mesma situação histórica do desencontro e mútua omissão à qual acabei de referir-me.

O confronto real das idéias de Hegel e Schopenhauer deve ser deduzido sistematicamente do puro conteúdo objetivo das suas filosofias, já que ele, de fato, não aconteceu. Sustentarei que, no interior das suas reflexões, Hegel - através da Dialética - e Schopenhauer - através da filosofia da Vontade de Viver - proporcionam elementos teóricos para pensar a relação vida/verdade. Proponho-me mostrar que ambos descobriram, de maneira independente e antagônica, dois mecanismos básicos da vitalidade, do movimento da vida, e que tal elucidação fornece subsídios para estudar as complexas relações entre esse movimento vital e as pretensões de verdade erigidas secularmente pelo pensamento filosófico. 


\section{I - HEGEL: a dialética como "vida do conceito"}

Não se trata, propriamente, de buscar, no interior da filosofia hegeliana, um "lugar" determinado no qual Hegel abordaria o problema das relações entre verdade e vida, mas de assinalar de que maneira, na própria revolução lógica hegeliana cujo núcleo reside na sua idéia de "conceito" - o pensamento funciona e se desenvolve à luz de um modelo "vital", de uma espécie de "bio-lógica do conceito". Trata-se de mostrar como o movimento dialético do conceito é, segundo Hegel, o próprio movimento do vivente, ou seja, mostrar, em definitivo, que a problemática verdade/vida perpassa toda a filosofia de Hegel e, portanto, não poderíamos encontrá-la meramente "exposta" em algum "lugar" de sua obra. "Não é o abstrato ou irreal... senão o real, que se põe a si mesmo e vive em si, o ser-aí no seu conceito. É o processo que gera e percorre seus momentos, e esse movimento em conjunto constitui o positivo e a sua verdade. Por conseguinte, esta implica igualmente o negativo em si... O que aparece, é o nascer e o perecer, que por si mesmo nem nasce nem perece, senão que é em si e constitui a realidade e movimento da vida da verdade"

Este tipo de afirmação é habitual na Fenomenologia do Espínto, mas também na Ciência da Lógica. Os conceitos "vivem", se "desenvolvem", ou pelo contrário, são "mortos", ficam "sem desenvolvimento", "sem substância", "inertes", etc. Na exposição filosófica tradicional, os conceitos são simplesmente adequados ou inadequados, apropriados ou inapropriados: como é que um conceito pode "viver" ou "morrer"? Poderíamos considerar esta exposição - esta apresentação "existencial" da lógica do conceito - como meramente metafórica, sendo sempre possível substituí-la por uma exposição tradicional, sem aquele elemento? Pretendo duvidar disso ao longo do presente trabalho.

Como fica testemunhado em numerosas citações, o elemento fundamental da "vida" do conceito é, segundo Hegel, o negativo. O negativo define o vivente enquanto tal, como podemos ler na Ciência da Lógica: “... o impulso em geral (apetição ou Nisus da mônada) não é outra coisa senão o fato de algo existir em si mesmo, e é a falta, o negativo de si mesmo, num único e idêntico aspecto. A identidade abstrata consigo mesma não é ainda nenhuma vitalidade senão que como o positivo é em si mesmo a negatividade, por isso sai fora de si mesmo e se coloca a si mesmo em processo de transformação. Portanto, algo é vivente na medida em que é, precisamente, essa força para tomar e sustentar em si a contradição". ${ }^{2}$

O negativo - conceito central da filosofia hegeliana - é o nervo principal do desenvolvimento dos conceitos mas, ao mesmo tempo, o próprio motor do desenvolvimento da vida. O negativo constitui, pois, a ligação filosófica entre conceito e vida. "... assim, o conceito tem-se desdobrado na sua absoluta desigualdade consigo mesmo...e o vivente é por si mesmo este desdobramento e possui o sentimento desta contradição, que consiste na dor. A dor é, por conseguinte, o privilégio das naturezas viventes; estas, sendo o conceito existente, são uma realidade da

HEGEL, Vorrede zur Phänomenologie des Geistes, p. 108. (Eđição bilíngüe francês-alemão).

HEGEL, Wissenschaft der Logik, II, 59. 
força infinita, quer dizer, são em si a negatividade de si mesmas...Quando se diz que a contradição não é pensável, ela pode sê-lo sobretudo na dor do vivente como existência efetiva".

Duas idéias parecem fundamentais nesta concepção "bio-lógica"·do conceito: a idéia do conceito como uma "recuperação", como um "processo de apropriação"; e a idéia do conceito como desenvolvendo-se de maneira necessária, carregando a sua própria negatividade. Comentarei brevemente estas idéias.

A primeira coloca que viver não se caracteriza por uma "posse", mas por um esforço de recuperação do próprio ser que ultrapassa a sua imediatidade, na medida em que tudo aquilo que simplesmente "somos" deverá ser negado para ser vivido como propriamente nosso. Esta negação se desenvolve dentro de um processo que acarreta dor e esforço, absolutamente inevitáveis na medida em que o ser vivente pretenda experimentar-se a si mesmo como tal. Este processo "negativo" não é, pois, uma anomalia ou uma raridade, mas o próprio funcionamento normal do conceito. Não será considerado como "vida" a daquele ser inerte e imediato que nunca se põe em risco por medo do esforço e da dor (ou seja, a vida mansa do filho na confortável casa dos pais). A "morte"de um conceito poderá, assim, acontecer em dois momentos diferentes: por um processo de envelhecimento, de esgotamento do seu próprio conteúdo, ou, pura e simplesmente, apagando-se como conceito que se recusa a desenvolver-se, optando pela sua mera positividade, morrendo nela sem desenvolvimento (morrendo, por assim dizer, antes de nascer). Tentar evitar a morte será, precisamente, a maneira como o conceito a encontrará.

A segunda idéia - que caracteriza, segundo Hegel, a vitalidade - é a de que o conceito carrega, de maneira necessária, a sua própria negatividade, ou seja a possibilidade de uma negação, independente do fato empírico e eventual dessa negatividade ser ou não colocada por alguém. Um conceito se desenvolve não para atingir uma certa verdade objetual, nem para declarar "inadequado" algum outro conceito (e "falsas" as sentenças em que o mesmo aparece), nem para "resolver" alguma coisa, mas, pura e simplesmente, por necessidade interna. Quando um conceito é colocado, ele não é "afirmado como verdadeiro", no sentido aristotélico tradicional: "p" não é, pois, idêntico com “ 'p' é verdadeiro". Devese fazer uma diferença entre colocar uma idéia e afirmá-la como verdadeira (ou "asseverá-la"). Dentro da concepção hegeliana, inclusive, aquilo que é imediatamente colocado jamais é verdadeiro, seja qual for o seu conteúdo semântico, na medida em que lhe falta o desenvolvimento que só poderá adquirir no processo das suas sucessivas colocações. (Em termos mais contemporâneos, e dentro de certas limitações, "colocar" um conceito poderia ser entendido como uma operação "pragmática". Hegel irá, mais tarde, reencontrar a dimensão semântica da verdade, porém redefinindo tal dimensão agora em termos do processo de desenvolvimento do conceito, e não mais em termos de conteúdos semânticos particulares.)

Este desenvolvimento dos conceitos não possui nenhuma outra "finalidade" além do autoconhecimento, a recuperação da vida num certo nivel de apropriação

3 HEGEL, W. der L., II, 424. 
e compreensão. $\mathrm{E}$ isso deve ser feito para quê? Esta pergunta deveria receber a mesma resposta que a pergunta: "para que viver?". Neste sentido, nem na argumentação nem na vida, "resolvemos" absolutamente nada. Se alguém ficasse insatisfeito diante da falta de finalidade da argumentação, deveria já ter ficado insatisfeito diante da total falta de finalidade da vida.

À luz desta leitura de Hegel, quero colocar aqui as relações entre os conceitos e seus sustentadores humanos finitos, que me parecem estar implícitas nesta concepção hegeliana da argumentação. O fenômeno mais espantoso e intrigante da argumentação filosófica consiste - numa perspectiva hegeliana - no fato de os filósofos defenderem as suas idéias, em vez de tentar, por exemplo, destruí-las. Poderíamos pensar, à luz da concepção dialética da argumentação, que somos meramente veículos das "nossas" idéias,as quais, de qualquer modo, apesar da nossa generosa "defesa", carregam inevitavelmente a sua própria negação. Por que motivo deveríamos defender ou atacar idéias? Pareceríamos não conformados apenas com viver os conceitos, também gostaríamos de possuir, através deles, um certo "objeto". E para possuí-lo, seria preciso recusar-se a negar certas idéias, embora tal negação implicasse o próprio desenvolvimento da sua "vida". Algumas idéias devem, pois, permanecer mortas, indefinidamente sustentadas. No "defender" e "atacar" idéias, tudo acontece como se a formalidade da vida fosse esquecida em favor de certos "conteúdos de estimação", de certas "verdades favoritas". Tais verdades são como elementos com um valor além do simples viver, como se desenvolver-se, autoconhecer-se, etc., não fossem estímulos suficientemente nobres para o pensamento, como se este partisse para a conquista de um certo "objeto" em nome do qual valesse a pena empreender o próprio desenvolvimento da vida. (Podemos sentir neste ponto a abertura de alguns dos lugares filosóficos mais típicos da crítica nietzscheana à noção de verdade.)

Mas, que impediria atacar os próprios pensamentos, argumentar contra eles, em vez de defendê-los? Se se trata, finalmente, de viver, de desenvolver os conceitos mediante a negação, por que aguardar que os outros neguem meus conceitos? Por que não poderia eu mesmo assumir essa tarefa? Por que não posso mostrar o sem-sentido, o absurdo, a incongruência, etc., dos meus próprios pensamentos, de maneira sistemática e não através de eventuais (e fingidas) "autocríticas"? Por que devo defendê-los? Defendê-los de quê? A mecânica da vida, de acordo com as intuições hegelianas, deve levar à negação dos conceitos, e não à sua conservação no positivo. Isto quer dizer que se um conceito se mantém teimosamente no positivo não há nenhum elemento no plano conceitual objetivo que permita isso, mas são certas características do sustentador as que permitem tal situação. E essa intervenção do sustentador poderia ser declarada ilegítima do ponto de vista da lógica interna de um conceito. No desenvolvimento do próprio conceito não deveria haver nenhum tipo de compromisso com o sustentador do mesmo. $O$ desenvolvimento de certo conceito, no caso extremo, poderia levar à própria morte do sustentador. Porém, essa morte o sustentador a encontraria no caminho de uma vida verdadeira, de acordo com os pressupostos de Hegel, posto que ela se apresentaria toda vez que o sustentador não se recusa ao negativo e, por conseguinte, 
não pretende conservar para ele uma pseudovida inerte e sem negações, capaz de garantir-lhe uma morte afirmativa e sem máculas.

Porém, se a dinâmica do pensamento, segundo Hegel, passa pelo negativo, deveríamos perguntar - nietzscheanamente - quanta negatividade pode suportar um existente humano, ou seja, até que ponto um existente pode ser "dialético" até o fim. O conceito, por si mesmo, deveria dar "tudo de si", enfrentar a maior quantidade possível de negações, enriquecer-se indefinidamente. Porém, eu, como sustentador finito desse conceito, deverei, mais tarde ou mais cedo, encontrar os limites da minha própria finitude. Ela me exige "parar" o processo dialético em algum ponto, o ponto no qual possa ser configurada a forma de vida que eu, existente abstrato finito, sou capaz de viver. Posso ser um argumentador profundamente interessado no desenvolvimento dos meus conceitos. Porém, devo igualmente ser um existente profundamente interessado, por exemplo, no meu próprio equilíbrio emocional, na continuidade do meu viver, na conservação da minha própria identidade, etc. Assim, o filósofo pode ser - como habitualmente nos contam as Histórias da Filosofia - 0 "buscador da verdade", mas com "algumas limitações primordiais": ele buscará apenas a verdade que não o desequilibre e a verdade que não o leve para a morte. A verdade terá os limites da saúde e da sobrevivência.

A concepção dialética da argumentação opera nitidamente a distinção entre a verdade, e aquele ponto eventual no qual o mero argumentador finito deve "parar" para consolidar a sua própria finitude, para preservar a sua própria identidade, a distinção entre a infinitude do desenvolvimento de um conceito e a finitude do seu sustentador humano. Desde este ponto de vista, deveria considerar-se profundamente suspeita uma argumentação que deixa seu eventual sustentador absolutamente "salvo" do seu próprio conteúdo crítico problematizador. Por que a argumentação deveria "poupar" a seu mero proferidor? Não é uma estranha e feliz coincidência que "a verdade" acabe coincidindo com as condições da própria sobrevivência? Um homem poderia morrer sem ter acabado de desenvolver um conceito. E um conceito poderia ficar exausto antes da morte do seu eventual sustentador. Se fôssemos analisar o plano dos puros conceitos, poderíamos mudar de filosofia como mudamos de roupa ou de moradia, poderíamos ser kantianos de manhã, empiristas lockeanos à tarde e spinozistas à noite. Por que isso não acontece? Não indica isso uma legítima confusão do lógico e do psicológico?

Acompanhados desta bagagem conceptual, quero tentar agora algo como um "corte schopenhauereano" da exposição hegeliana do conceito, dentro do escopo da problemática verdade/vida, tentando traçar algumas linhas de contato entre a filosofia da "vontade de viver" e a filosofia da "vida do conceito" de Hegel.

\section{II - SCHOPENHAUER: A representação como "vontade de viver objetivada" do conceito}

Uma idéia central na filosofia de Schopenhauer consiste em que o conhecedor de essências, o "buscador da verdade", o filósofo, é também, e primariamente, um corpo-vontade, um centro volitivo submetido inevitavelmente ao esforço e à dor. 
Hegel e Schopenhauer se encontram, assim, na idéia primordial de ser um princípio puramente formal, e de natureza vital, aquilo que norteia, de maneira não totaimente manifesta (através de certas "astúcias", dialéticas ou volitivas) a argumentação filosófica na sua declarada "busca da verdade": em Hegel, o princípio da negação dialética; em Schopenhauer, o impulso da vontade de viver. Ambos consideram, nesta perspectiva, que os conflitos humanos - dentro e fora do âmbito da filosofia - caem, nesse sentido, na ilusão dos seus puros conteúdos. No caso especial de Schopenhauer, os conflitos são antigos - ou arcaicos - e não nascem, certamente, no plano humano da representação conceptual, mas da própria dinâmica interna da vontade de viver: “...a vontade de viver se devora constantemente a si mesma e nas suas diferentes configurações constitui seu próprio alimento..." ${ }^{4}$.

Tanto quanto na filosofia dialética de Hegel, a noção tradicional - de natureza realista - da verdade fica problematizada, convidada a redefinir-se em termos de um processo vital. São, entretanto, os mecanismos desse processo aquilo que deverá diferenciar profundamente as posturas de ambos filósofos. Esta discussão seria um lugar adequado de confronto de idéias entre Hegel e Schopenhauer, mais além da luta política pelo reconhecimento intelectual, que hoje não mais nos interessa. Poderíamos imaginar aqui, à maneira de experimento, um diálogo ideal entre ambos filósofos acerca da questão das relações entre vida e verdade, mostrando ambos filósofos cooperativamente engajados num projeto de problematização radical - e revolucionária - da racionalidade filosófica tradicional. Esse diálogo ideal poderia decorrer, talvez, da seguinte maneira:

Schopenhauer. Expliquei, na minha obra fundamental, que a representação - conceptual ou intuitiva - não possui qualquer tipo de independência metafísica. Embora do ponto de vista da representação a totalidade do mundo me pertença de acordo com o ponto de vista idealista clássico - e até meu próprio corpo se me apresente como um corpo-representação, como corpo entre corpos, afirmei claramente, no final do Livro I do primeiro volume da minha obra magna, que apenas "duas coisas são totalmente inexplicáveis, quer dizer, irredutíveis à relação que o princípio de razão expressa: em primeiro lugar, o próprio princípio de razão, em suas quatro configurações, porque ele é o princípio de toda explicação... e em segundo lugar, aquilo que não é acessivel através dele, mas do qual provém o originário de todos os fenômenos: é a coisa-em-si, cujo conhecimento não está em absoluto subordinado ao princípio de razão"s. Aquilo irrepresentável é, em primeiro lugar, meu próprio corpo enquanto corpo-vontade, sujeito ao prazer e à dor, ao mecanismo da vontade de viver. A vida consciente, cognitiva será agora vista como um tipo especial de objetivação da vontade de viver. Eu não posso absolutamente aceitar da filosofia do meu colega e amigo Hegel, aquela pseudoindependência entre os planos conceptuais e os planos "instintuais" e volitivos. Por exemplo, Herr Hegel escreve, na sua Ciência da Lógica, que Anaxágoras é celebrado como o primeiro a ter afirmado a idéia de ser o Nous, o pensamento, o princípio do mundo, e que a essência do mundo devia ser determinada como o pensamento. Ele colocou desta forma o fundamento de uma visão intelectual do

4 SCHOPENHAUER, Die Welt als Wille und Vorstellung, I, 175.

6 SCHOPENHAUER, Die Welt, I, 96. 
universo, cuja forma deve ser a lógica ${ }^{6}$. Segundo a filosofia de Hegel, a síntese final do processo é, pois, de natureza conceptual, o que fica claro na exposição fenomenológica do seu pensamento, na qual a substância que faz parte essencial do conteúdo da Religião e da Arte, deve ser recuperada, segundo Hegel, pela Filosofia no plano do puro conceito. Mas afirmei, no volume II, de $O$ mundo como vontade e representação, que "... todos os filósofos que me precederam, do primeiro até o último, colocaram a autêntica essência do humano, ou a sua chave, na.consciência cognitiva, e dessa maneira têm representado o eu... primeira e essencialmente como cognoscente, como pensante, e só depois, de maneira secundária e derivada, como volitivo. Só a minha filosofia pode conduzir para fora destes dilemas, como a primeira a colocar a autêntica essência do humano não na consciência senão na vontade, que não está ligada essencialmente com a consciência"”. A meu ver, Herr Hegel não escapa, assim, da tradição intelectualista em filosofia ao pretender um desfecho conceptual do mundo, apresentado por ele como um processo de "autoconhecimento". Porém, a minha filosofia mostra que todo e qualquer processo de autoconhecimento está necessariamente mediado pelo caráter inconsciente da vontade de viver. Essa pretensa "transparência" do sujeito consigo mesmo ignora esse caráter inconsciente, acontecendo tudo como se não houvesse inconvenientes básicos para efetivamente realizar tal autoconhecer-se. A vontade de viver não possui nenhum tipo de finalidade, e muito menos uma finalidade em termos de "autoconhecimento", sendo que na própria operação cognitiva dá-se a total subordinação da representação à vontade de viver. Tentei mostrar que a única maneira de fugir desse mecanismo não poderia nunca ser um procedimento cognitivo, mas uma ascese ética (no ascetismo) ou estética (no gênio artístico), através de representações puras que não são já "cognitivas" no sentido usual. A vontade de viver não permite, então, uma síntese intelectual, cognitiva ou autocognitiva. Apesar, pois, da apresentação "existencial" da filosofia hegeliana do conceito, como um conceito que "vive", essa "vida" já está irremediavelmente definida em termos intelectualistas, ignorando o próprio princípio primordial da vida, que é volitivo e inconsciente. É, pois, impossível essa reconciliação final num "saber" absoluto, como descrita por Hegel.

Hegel. As observaçōes de Herr Schopenhauer enriquecem, sem dúvida, a discussão acerca da questão da racionalidade e sua relação com os elementos instintuais - que eu prefiro denominar "apetitivos" - e gostaria de posicionar aqui a filosofia dialética perante críticas vindas de toda e qualquer postura filosófica baseada nesses impulsos como sendo prioritários. Schopenhauer acha que eu não consigo entender 0 fator "inconsciente" dentro do processo autocognitivo. Eu responderia dizendo que ele manifesta uma radical incapacidade para entender 0 fator dialético desse mesmo processo. Isso já se mostrou claramente no seu penetrante opúsculo de 1813, Sobre a quádrupla raiz do princípio de razão suficiente, onde ele me acusa - deixando de lado excessos verbais, irrelevantes para a questão - de ter erigido novamente uma razão que teria, segundo ele, "a capacidade direta e intuitiva de captar objetos, ou ,como ele o diz textualmente, "uma intui-

HEGEL, W. der L, I, 31.

SCHOPENHAUER, Die Welt, II, 222/23. 
ção racional direta do absoluto, ou do infinito". Porém, se Schopenhauer lesse mais cuidadosamente a minha Ciência da Lógica, ou ainda as primeiras páginas da Fenomenologia do espirito, concordaria plenamente com a minha própria crítica contra todo tipo de "intuição intelectual" que pretendesse atingir os objetos de maneira "imediata" e sem esforço, sendo para mim a noção de "absoluto" não mais aquela noção teológico-mística (que se pode encontrar, por exemplo, nos escritos de Schelling) mas uma noção elaborada historicamente pelo trabalho racional efetivo dos homens pensantes. Como seria possível confundir uma razão dialética com uma "intuição" capaz de captar "diretamente" o supra-sensível, sendo que toda a minha filosofia dialética se constitui como uma crítica a todo e qualquer tipo de imediatez? Gostaria de mostrar a Schopenhauer, em primeiro lugar, como as suas observações baseadas na primazia da Vontade de Viver ignoram a dialética de maneira fundamental, o que faz com que a minha filosofia não seja atingida, em absoluto, pelas suas críticas. E, em segundo lugar, quero mostrar que Schopenhauer também utiliza as mediações dialéticas - e não poderia deixar de utilizá-las - na sua própria filosofia do conceito.

Se estivesse eu falando do conceito num sentido clássico, precisamente aquele que Schopenhauer apresenta no Livro I da sua magna obra, suas críticas seriam perfeitamente pertinentes. Aquele conceito é apenas um resumo de representações intuitivas. Porém, já no Prefácio da segunda edição da minha Ciência da Lógica, se poderá encontrar uma crítica fundamental à teoria lógica aristotélica e, sobretudo, à concepção clássica do conceito como fruto de um processo abstrativo, generalizador da experiência, suscetível de definição unívoca. Defino, assim, um novo tipo de "conceito", que poderíamos chamar, se quisermos, de "conceito dialético". Esta nova concepção do conceito está fundamentalmente baseada numa nova maneira de entender a operação de negação. Schopenhauer afirma que da Vontade de Viver não pode haver nenhuma representação e eu concordo plenamente com ele... enquanto nos mantivermos dentro da concepção clássica do conceito: não pode haver um conceito aristotélico da vontade de viver, isso é tudo o que Schopenhauer consegue demonstrar. Porém, há e deve haver um conceito dialético da Vontade de Viver, enquanto também ela deve ser negada e desenvolvida num processo dialético-histórico, para ela ser um genuíno conceito filosófico, como pretende Schopenhauer.

Schopenhauer me acusa de ter postulado uma faculdade de captação "imediata", mas ele afirma em numerosos pontos da sua exposição, ao longo de toda a sua obra, o caráter "imediato" da Vontade de Viver - como uma "coisa-emsi" - muito próxima de nós, elemento "familiar" que se manifesta "diretamente" em nosso interior, etc. Mas, precisamente, a minha noção de racionalidade não aceita imediatos de nenhum tipo, sob pena de eles virem a transformar-se em novas entelequias ou "essências" imutáveis do mundo, como aquelas que a dialética transcendental kantiana - que Schopenhauer me acusa de desrespeitar tentou criticar a eliminar para sempre da cena filosófica. É Schopenhauer, e não eu, pois, quem estaria voltando, neste sentido, à filosofia pré-crítica, e à pretensão de definir a "verdadeira essência do mundo", com a única diferença de que uma

SCHOPENHAUER, Die Welt, II, 222/3. 
tal essência não seria mais "intelectual" (um Nous) mas "volitiva". Qualquer noção, porém, que não for processada por uma razão negativa, se transformará inevitavelmente num novo "princípio" ou "fundamento do mundo", como os da metafísica dogmática criticada por Kant.

Por outro lado, é falso que a minha filosofia não problematize o eu da consciência, porque esse eu fica tão submetido à dialética como qualquer outro conceito. Pode-se ler, por exemplo, na "Introdução à doutrina do ser", a primeira parte da minha Ciência da Lógica: "O eu, essa autoconsciência imediata, aparece, em primeiro lugar, parte como um imediato, parte como algo conhecido num sentido muito mais elevado do que qualquer representação... Não obstante isso, esse eu puro não é mais um imediato, nem aquele eu conhecido e costumeiro da nossa consciência... para mostrar-se como verdadeira exigência, seria preciso que 0 movimento progressivo do eu concreto, indo desde a consciência imediata para o saber puro, fosse, através da sua própria necessidade, nele mesmo mostrado e representado"'. Portanto, na minha filosofia, não poderia tratar-se nunca de um consciencialismo cartesiano - que a lógica dialética critica abertamente - mas de uma recuperação conceptual, em sentido dialético, de todos os conceitos, incluído o conceito de consciência, incluídos todos os elementos "intelectualistas" da tradição filosófica mencionados por Schopenhauer, e incluída também, claro está, a sua "Vontade de Viver".

Por último, quero mostrar que, apesar das suas críticas, Herr Schopenhauer também pensa dialeticamente na sua exposição da teoria da Vontade de Viver. De fato, como ele mesmo o diz textualmente, toda a sua filosofia poderia ser considerada como um "autoconhecimento da Vontade de Viver": "Enquanto formos a própria vontade de viver, aquele elemento último poderá ser conhecido e indicado por nós apenas negativamente... [isso] nos impede seu conhecimento e, ao mesmo tempo, é aquilo que nos dá a possibilidade de todo o nosso efetivo conhecimento, isto é, o mundo como representação, ou a objetividade da vontade. Assim, o mundo é o autoconhecimento da vontade" ${ }^{\prime 10}$. De acordo com a sua filosofia, a Vontade de Viver anda como cega através das suas Gestalten pré-humanas, e ao chegar ao homem ela ganha uma espécie de "farol" - a representação - ponto no qual a vontade se conhece a si mesma enquanto tal. $\mathrm{O}$ homem é, pois, a cena desse importante autoconhecimento. Porém, o que é decididamente "dialético" no pensamento de Schopenhauer é a sua obtenção da "representação pura", nos livros III e IV da sua obra magna. Com efeito, pelo livro I conhecemos a representação ordinária, submetida à vontade de viver. Num segundo momento, a vontade de viver nega o mundo como representação, no sentido de colocar o irrepresentável, a negação da própria primeira frase do seu livro, "o mundo é a minha representação". Porém, mais adiante, Schopenhauer negará essa própria Vontade de Viver (a negação da negação) surgindo então, de novo, a representação, mas não mais aquela primeira, senão a que ele chama "representação pura", que carrega dentro de si a negação da representação originária. Esta "dialética da pura representa-

\footnotetext{
- HEGEL, W. der L., I, 61.

10 SCHOPENHAUER, Die Welt, I, 485.
} 
ção" não é eventual na filosofia de Schopenhauer, mas um dos elementos fundamentais da mesma.

Se continuássemos este experimento filosófico, Schopenhauer poderia reargüir, neste ponto, no sentido de mostrar que mesmo uma concepção enriquecida do conceito, na linha "dialética" ou alguma outra, continuaria mantendo-se dentro da tradição intelectualista por ele criticada, evidenciando-se por parte de Hegel um profundo desconhecimento das características peculiares da Vontade de Viver. A intuição principal de Schopenhauer consiste em que Vontade e Representação são dois acessos radicalmente diferentes ao mundo e que, mesmo enriquecendo ad infinitum a teoria do conceito, jamais atingiremos com isso o âmbito da Vontade de Viver. Vontade não é simplesmente representação enriquecida, mas o fundamentalmente outro da representação. A dor não poderia ser conceptualmente negada, nem mesmo "dialeticamente". $\mathrm{E}$, como contra-ataque, qualquer representação, mesmo enriquecida, será, inevitavelmente, objetivação da Vontade de Viver, um investimento das forças vitais: a própria "dialética" será possível apenas como objetivação dessa força primordial. Porém, a Vontade de Viver não condiciona a representação via "fundamento", como fazem muitos dos princípios da metafísica dogmática clássica, mas pela via de uma espécie de "condição pulsional" de possibilidade. Dentro da problemática das relações vida/verdade, o conceito hegeliano, embora não orientado na direção da verdade como correspondência, se encaminha não obstante na direção de uma verdade como Totalidade. E tal direcionamento poderia, inclusive - como Kierkegaard viu - exigir a eliminação "dialética" da vida particular do existente em benefício da Totalidade. A dialética se mostraria, assim, invulnerável, ela não poderia nunca ser negada e, nesse sentido - de acordo com Schopenhauer - seria ela (e não a Vontade de Viver) o princípio metafísico pré-kantiano a ser criticado. Porém, a Vontade de Viver pode ser negada, só que não conceptualmente, mas através de uma certa forma de vida, no gênio artístico ou no ascetismo. Mas essa "negação" da Vontade de Viver, ao ser possível somente de forma não conceptual, implica igualmente uma negação do conceito, no sentido do abandono da intencionalidade cognitiva em benefício de intencionalidades éticas ou estéticas. É nesse ponto onde a verdadeira primazia da vida sobre a verdade se põe de manifesto. Não era, pois, suficiente conceber a vida como negação do imediato, enquanto uma tal concepção se mantivesse, apesar de tudo, no caminho da verdade, mas era preciso conceber o próprio conceito como Vontade de Viver, cega e sem finalidade.

Nesse sentido, a filosofia schopenhauereana do conceito se mostra muito mais "otimista" do que a hegeliana. Considero, em geral, superficial a caracterização do pensamento de Schopenhauer como "pessimista". Com efeito, a impossibilidade de negar a dialética indica algo como uma intencionalidade "suicida" da mesma. Pelo contrário, há em Schopenhauer uma negação explícita da intenção suicida em todos os planos, no sentido da possibilidade de fugir da dinâmica tédio/dor através de uma forma de vida, não através de um argumento conceptual, nem de uma supressão física, literal, do existente. Tal possibilidade permanece fechada para Hegel, para quem a dor (e, presumivelmente, também o tédio) é o 
"privilégio" irrenunciável das naturezas viventes. No "pessimista" Schopenhauer acharemos, paradoxalmente, subsídios para fugir deste sinistro privilégio.

Este diálogo imaginário poderia continuar, mas é previsível pensar que Schopenhauer continuaria rejeitando a intelectualização da Vontade de Viver, e Hegel continuaria a denunciar o caráter pseudo-imediato e não dialetizado desta mesma noção. Pois trata-se de dois mecanismos formais (Dialética e Vontade de Viver), no sentido de agirem além de conteúdos determinados: todo e qualquer conteúdo deverá carregar a sua própria negatividade e todo e qualquer conteúdo deverá objetivar a Vontade de Viver. Em ambos os casos, os conteúdos estão rigorosamente submetidos a mecanismos vitais inexoráveis. Dialética e Vontade de Viver são apresentados como as características fundamentais do processo da vida, mas ambos os princípios aparecem como antagônicos e irreconciliáveis: a dialética nega o inconsciente, a Vontade de Viver nega a dialética.

\section{EPÍLOGO: Gênios paralelos}

Hegel e Schopenhauer são dois caminhos possíveis de ultrapassagem dos limites impostos por Kant à racionalidade. A partir de agora, se formos honestos, não poderemos ignorar essas duas problematizações, mesmo que seja para reconstruir a racionalidade tradicional sobre outras bases, porém não sem antes examinar cuidadosamente as duas vertentes críticas que partem de Hegel e Schopenhauer. Hegel mostra que a racionalidade não poderia entender-se a si mesma na sua pura positividade, mas somente através de um processo no qual ela enfrenta as suas necessárias negações. Schopenhauer mostra que a racionalidade não poderia entender-se a si mesma na sua pura natureza representacional, mas somente através da mediação da Vontade de Viver inconsciente. Dessa dupla vertente deverá sair não, certamente, o "irracionalismo", mas uma teoria enriquecida da racionalidade.

Sem dúvida, ambos filósofos serão afetados pelas críticas contemporâneas contra as filosofias da consciência e os fundamentalismos de tipo metafísico em geral: não se poderá negar que, apesar do seu gênio, Hegel e Schopenhauer são filósofos da sua época e, por conseguinte, ainda ligados a esquemas tradicionais de pensamento. Apesar de equívocos e desencontros históricos, ambos problematizam a racionalidade de maneira crítica e renovadora, porém antagônica. Tratase, pois, de dois gênios rigorosamente paralelos, que se ignoram ou malinterpretam, como se o espaço filosófico do século XIX tivesse sido demasiado pequeno para abrigar a ambos. Foi impossível que uma mesma época, por mais criativa que fosse, pudesse assimilar, em tão poucos anos, duas revoluções filosóficas tão díspares e audaciosas.

O desencontro Hegel-Schopenhauer se ameniza, de alguma maneira, muito tempo depois, através das vinculações críticas entre Marxismo e Psicanálise, ou entre as estruturas reflexivas da Ideologiekritik e a análise do inconsciente. Se considerarmos as raízes hegelianas do Marxismo e as vinculações schopenhauereanas com a teoria do desejo de Freud (como lhe foram mostradas ao próprio Freud por Otto Rank) esta vinculação Marxismo-Psicanálise poderia interpretar-se como 
uma espécie de encontro de ultratumba entre Hegel e Schopenhauer. Talvez o encontro mais recente entre dialética e inconsciente tenha acontecido em fevereiro de 1954, a partir do convite feito por Jacques Lacan a Jean Hyppolyte em torno da discussão da Verneinung. Tentando o esclarecimento do que Lacan chama "a dialética do desejo", ambos identificam - através da análise do texto clássico de Freud - a negação como uma característica fundamental do inconsciente. Esta lenta reconciliação - que não suprime o antagonismo na medida em que nunca é totalmente consumada - mostra até que ponto foi explicável a mútua omissão dos dois filósofos aqui convocados.

Talvez a melhor maneira de concluir esta reflexão seja deixar a palavra com Nietzsche: “... Hegel e Schopenhauer... esses dois gênios-irmãos, hostis em filosofia, que tendiam para os pólos opostos do espírito alemão, e que por isso mesmo se faziam mutuamente injustiça, como só dois irmãos podem cabalmente fazê-la”. (Além do bem e do mal, 252).

\section{Referências bibliográficas}

ASSOUN, Paul-Laurent. Freud, a filosofia e os filósofos. Rio de Janeiro: Francisco Alves, 1978.

CABRERA, Julio. A leitura schopenhauereana da segunda Crítica. Revista Filosofia Política, n. 4, L\&M, Unicamp-UFRGS, 1987. . Projeto de Ética negativa. São Paulo: Mandacarú, 1990. . Crítica de la Moral afirmativa. Barcelona: Gedisa, 1996. Wissenschaft der Logik. Felix Meiner Verlag, 1975. 2 v.

Phénomenologie de l'esprit. Préface. Edição bilingüe francês-alemảo, tradução, introdução e notas de Jean Hyppolite. Paris: Aubier-Montaigne, 1978.

HYPPOLITE, Jean. Comentario hablado sobre la Vemeinung de Freud. In: LACAN, J. Escritos 2. 4. ed. México: Siglo XXI, 1978.

SCHOPENHAUER, A. Über die vierfache Wurzel des Satzes vom zurreichenden Gunde. 2. ed. Felix Meiner Verlag, 1970. . Die Welt als Wille und Vorstellung. Wiesbaden, Eberhard Brockhaus Verlag, 1949. 2 v. 